\title{
Study on Optimum Free-face Condition of Cutting Hard Rock with Tunnel Boring Machine Hob
}

\author{
Xuhui Zhang ${ }^{1}$, Yashi Liao ${ }^{1 *}$, Zhongxiang Chen ${ }^{1}$, Yimin Xia², Kui Zhang ${ }^{3}$ \\ ${ }^{1}$ College of Engineering and Design, Hunan Normal University, Changsha, 410081, China \\ ${ }^{2}$ State Key Laboratory of High Performance Complex Manufacturing, Central South University, Changsha 410083, China \\ ${ }^{3}$ School of Mechanical Engineering, Xiangtan University, Xiangtan, 411105, China \\ * Corresponding author, e-mail: liaoyashi0000@csu.edu.cn
}

Received: 23 November 2020, Accepted: 18 January 2021, Published online: 21 January 2021

\begin{abstract}
To explore the rock-breaking characteristics of cutting hard rock under free-face condition by tunnel boring machine (TBM) hob and obtain the optimum free-face condition, the rock-breaking processes such as crack propagation, amount of micro crack and reaction force with penetration depth are first investigated based on discrete element simulation method. Then, the crack length, rock chip area, specific energy consumption etc. with different free-face spacing $(\mathrm{S})$ and free-face height $(\mathrm{H})$ are studied combined with rockcutting simulation and experiment. The research results show that the formation of the rock chip under free-face condition by TBM hob is driven by tensile failure, and it exists an optimum free-face condition with the $\mathrm{S}$ of $80 \mathrm{~mm}$ and the $\mathrm{H}$ of $200 \mathrm{~mm}$ to promote main crack propagation and enhance the rock-cutting efficiency, which can provide a reference for the application of rock-breaking technology under the free-face.
\end{abstract}

Keywords

TBM hob, free-face, free-face spacing, free-face height

\section{Introduction}

Tunnel boring machine (TBM) is the main tunnel construction equipment, which can excavate tunnel safely, economically and efficiently. Generally, TBM mainly depends on the TBM hob mounted on the TBM cutterhead to touch and cut rock. Consequently, the rock-cutting performance of the TBM hob directly determines the overall tunneling performance of TBM.

To know the rock-cutting characteristics of the TBM hob clearly, a large number of researches have been performed based on the simulated and experimental methods. For example, Innaurato et al. [1] and Ma et al. [2] established two-dimensional numerical model to analysis rock-cutting process of the TBM hob based on finite element method. Zhu et al. [3], Moon and Oh [4], Liu et al. [5] and Naghadehi and Mikaeil [6] simulated the rock penetrating process of the TBM hob and obtained the crack propagation law based on two-dimensional discrete element method. Some three-dimensional numerical model related rock cutting by the TBM hob have also been built to investigate the rock-cutting laws regarding rock-cutting force and rock-cutting efficiency of the TBM hob.
Choi and Lee [7] studied the rock-cutting forces of the TBM hob through three-dimensional particle discrete element method. Geng et al. [8] and Xiao et al. [9] presented the change laws of the rock-cutting forces of the TBM hob according to three-dimensional finite element method. Cho et al. [10] studied the optimal cutting spacing of the TBM hob considering the rock-cutting efficiency based on three-dimensional finite element method. In short, the research results obtained through the numerical simulations greatly contribute to the understanding of rock-cutting characteristics of the TBM hob.

Compared with simulated method, the experimental method can provide more intuitive and reliable results to understand the rock-cutting process since the cutting condition by TBM hob in the laboratory is the same as that at the project site, and the experimental results can be directly used in TBM engineering. For example, Liu et al. [11-12] and Lin et al. [13] performed a series of rock-cutting tests to analyze the effects of cutting spacing, penetration depth and cutting sequence of the TBM hob on rock-cutting efficiency. Pan et al. [14] analyzed the rock-breaking force and 
rock-breaking efficiency of the TBM hob in different cutting spacing and penetration depth through linear cutting machine. Yang et al. [15] and Yin et al. [16] performed rock-cutting experiments and investigated the crack characteristic of the jointed rock beneath the TBM hob. Ning et al. [17] and Xia et al. [18] explored the rock-cutting performance of the TBM hob with different blade width and cutting parameters based on linear cutting tests. Undoubtedly, it can be seen that it exists a lot of researches about rock-cutting tests of the TBM hob and it can provide good guidance for improving rock-cutting performance of the TBM hob from the above analysis.

With the fast advancement of underground space, the rock strata encountered by the TBM hob, especially for deep strata, become more and more complex, such as high compressive strength and abrasive strata. When the TBM hob cuts rock with uniaxial compressive strength over $140 \mathrm{MPa}$, the cutting force of the TBM hob can easily exceed $320 \mathrm{kN}$, and the penetration depth cannot exceed $1 \mathrm{~mm}$ generally, which drastically reduces the rock-cutting efficiency and life of the TBM hob. Consequently, it is difficult for the traditional cutting ways of the TBM hob to cut such a complex rock stratum. To overcome this situation, some new rock-cutting methods concerning the TBM hob are gradually introduced. Tan et al. [19] and Xia et al. [20] put forward a kind of rock-cutting method of the TBM hob with the combination of static and impact loads. Hassani et al. [21] and Lu et al. [22] explored the effects of microwave irradiation on rock-breaking characteristics and recommended a new rock-cutting method of the TBM hob assisted with microwave. Ciccu and Grosso [23] investigated a rock-cutting method of the TBM hob assisted with water jet and discovered this method can raise the rock-cutting performance of the TBM hob significantly. Recently, China Railway Engineering Equipment Group Co. Ltd designed a new kind of TBM based on the water-jetassisted rock-cutting technology, as shown in Fig. 1, which has been applied to Wan'anxi water diversion project in Longyan City. For this new kind of TBM, both the TBM hobs and water jet nozzles are mounted on the TBM cutterhead, and the water jet can cut a deep gap, namely freeface, to assist the TBM hob to cut the rock.

The diagram of the water-jet-assisted rock-cutting technology with the TBM hob is illustrated in Fig. 2, the water jet first cuts rock to produce a free-face, and then the TBM hob cuts the rock near the free-face to raise the rock-cutting performance of the TBM hob. This kind of rock-cutting technology is actually to provide a free-face for the TBM hob, and it is not hard to found that the free-face spacing $(S)$ and free-face height $(H)$, as shown in Fig. 2, are the main key parameters which influence the rock-cutting performance of the TBM hob under the free-face condition. Unfortunately, there are a few relevant researches about the rock-cutting characteristics of the TBM hob under the freeface condition [24]. In view of above, the rock-breaking process under the free-face condition by TBM hob and the influences of the $S$ and the $H$ on the rock-cutting laws of the TBM hob are investigated according to the numerical and experimental method in this paper to obtain the optimum cutting condition of the TBM hob under the free-face condition, which can provide a good reference for the application of rock-cutting technology under the free-face by the TBM hob, such as the water-jet-assisted rock-cutting method.

\section{Numerical model}

\subsection{Calibration of hard rock}

The discrete element simulation method is used to simulate the rock-cutting process including crack formation and propagation processes. The rock sample is simulated by the disk particles in the discrete element simulation. To reflect

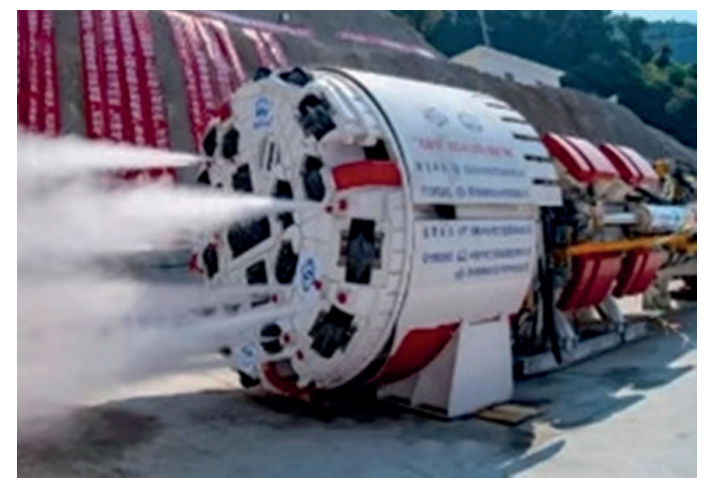

Fig. 1 New kind of TBM

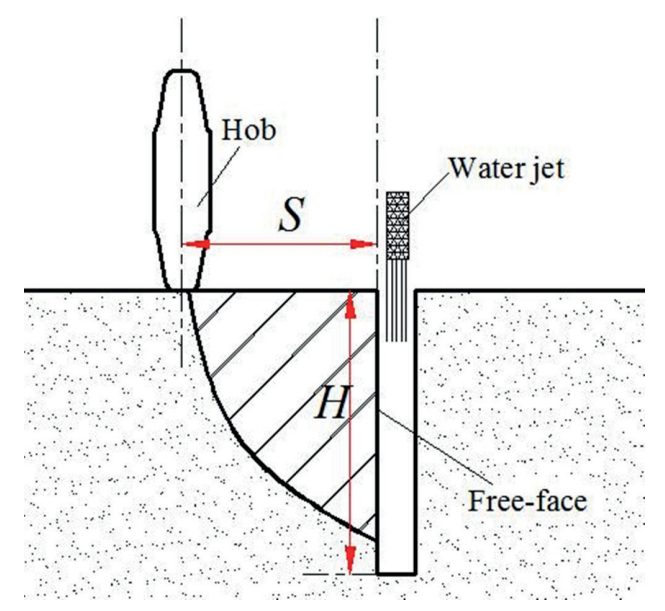

Fig. 2 Diagram of water-jet-assisted rock-cutting method 
the mechanical properties of the rock sample, some contact models including contact-bonding model and parallel-bonding model etc. should be given to the particles in the rock sample. In this paper, the contact-bonding model is selected to describe the contact properties between the particles since it has been proved that this model can simulate the rock cutting process of the TBM hob effectively. The contact-bonding model consists of bond and contact parameters. The bond parameters refer to the tangential strength and normal strength between particles. When the tangential or normal stress exceeds the tangential or the normal strength of the particles, the bond between two particles will fail and a shear or tensile crack will be produced. The contact parameters refer to the contact modulus and contact stiffness ratio, which can determine the relationship between displacement and stress of the particles.

To simulate the hard rock accurately, the micro mechanical parameters including bond and contact parameters of the particles in the discrete element simulation should be determined firstly according to the macro mechanical parameters of the rock sample including uniaxial elastic modulus, tensile strength, compressive strength, etc. The gneiss is chosen as the hard rock sample which is widely encountered in TBM engineering in this paper. A large number of standard samples of the gneiss are tested according to the uniaxial compression and Brazilian splitting experiments, then the macro mechanical parameters of the gneiss are obtained, as illustrated in Table 1. It presents that the rock sample is a typical hard rock whose uniaxial compressive strength is about $145 \mathrm{MPa}$. On this foundation, a large number of uniaxial compression and Brazilian splitting simulations are performed to match the above macro mechanical parameters. Finally, the appropriate micro mechanical parameters of the gneiss in the discrete element simulation method are obtained, as shown in Table 2.

Table 1 Macro mechanics parameters of the gneiss

\begin{tabular}{lc}
\hline Rock density $\left(\mathrm{kg} \cdot \mathrm{m}^{-3}\right)$ & 2520 \\
Elastic modulus $(\mathrm{GPa})$ & 62.5 \\
Tensile strength $(\mathrm{MPa})$ & 6.72 \\
Uniaxial compressive strength $(\mathrm{MPa})$ & 145.2 \\
\hline
\end{tabular}

Table 2 Micro mechanics parameters in simulation

\begin{tabular}{lc}
\hline Particle density $\left(\mathrm{kg} \cdot \mathrm{m}^{-3}\right)$ & 3375 \\
Tangential strength $(\mathrm{MPa})$ & 100 \\
Normal strength $(\mathrm{MPa})$ & 100 \\
Tangential stiffness $\left(\mathrm{N} . \mathrm{m}^{-1}\right)$ & $7.52 \times 10^{10}$ \\
Normal stiffness $\left(\mathrm{N} \cdot \mathrm{m}^{-1}\right)$ & $1.88 \times 10^{11}$ \\
\hline
\end{tabular}

\subsection{Establishment of the cutting model under free-face condition}

Considering the rock-breaking process is dominated by the penetration of the TBM hob, only the penetration process of the TBM hob under the free-face condition is studied [25-27]. The numerical model of cutting rock by TBM hob under the free-face condition is presented in Fig. 3. The rock sample with 50385 balls is generated according to the micro mechanical parameters in Table 2, the width and height of this rock sample are set to 400 and $300 \mathrm{~mm}$ regarding the boundary effects and the simulation time [28-29]. The left and bottom sides of the rock sample are restricted by walls, the top and right sides of the rock sample are namely working-face and free-face, as shown in Fig. 3. It should be pointed out that some of the right side of the rock sample is also restricted to achieve different cutting conditions. The spacing between the free-face and the middle of the hob blade is the free-face spacing $(S)$, and the height of the rock sample which is not restricted by the right wall is the free-face height $(H)$, as depicted in Fig. 3. The TBM hob with a blade width and blade angle of $20 \mathrm{~mm}$ and $20^{\circ}$, respectively, is simulated by a rigid wall and it is contacted with the working-face in the initial state. The vertical distance between the hob tip and the end point of the main crack is defined as crack length. The values of $S$ are varied from $20 \mathrm{~mm}$ to $120 \mathrm{~mm}$, and the values of $H$ are changed from $50 \mathrm{~mm}$ to $300 \mathrm{~mm}$, which are shown in Table 3. In addition, the penetration depth of the TBM hob is set to $6 \mathrm{~mm}$ based on a large amount of TBM construction data.

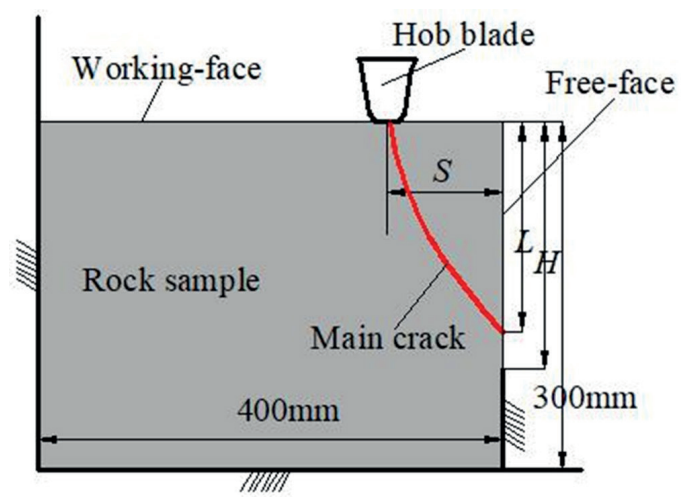

Fig. 3 Numerical cutting model by TBM hob under free-face condition

Table 3 Simulation values of free-face spacing and free-face height

\begin{tabular}{lc}
\hline Simulation variable & Values \\
\hline Free-face spacing $(\mathrm{mm})$ & $20,40,60,80,100,120$ \\
Free-face height $(\mathrm{mm})$ & $50,100,150,200,250,300$ \\
\hline
\end{tabular}




\section{Numerical results and discussions}

\subsection{Rock-cutting process by TBM hob under free-face condition}

To understand the rock-breaking characteristics under the free-face condition by TBM hob clearly, the rock-breaking process is investigated based on the penetration process of the TBM hob. Fig. 4 shows the crack initiation and propagation processes during the penetrating process of the TBM hob when the values of $S$ and $H$ are $60 \mathrm{~mm}$ and $300 \mathrm{~mm}$. Meanwhile, the amount of micro crack in the rock sample and the reaction force of the TBM hob with penetration depth are recorded in Fig. 5 and Fig. 6, respectively.

While the penetration depth is lower than $0.2 \mathrm{~mm}$, no crack is generated in the rock sample, as shown in Fig. 4(a), and its state corresponds to point $a$ in Fig. 5. In this stage, there is only elastic deformation in the rock sample without internal fracture, resulting in a linear increase of vertical force of the TBM hob, as shown in Fig. 6. With the increase of the penetration depth, the rock under the hob blade is crushed and a dense nucleus is produced. The zone of the dense nucleus consists of a certain amount of shear crack marked by blue point, as illustrated in Fig. 4(b). It also can be observed that the amount of the shear micro crack is larger than that of the tensile micro crack when the penetration depth is less than $0.4 \mathrm{~mm}$, as shown in Fig. 5, indicating that the formation of the dense nucleus is dominated by shear failure. Meanwhile, as illustrated in Fig. 4(b), macro crack begins to appear and initiate as the penetration depth increases to $0.4 \mathrm{~mm}$. For this given penetration depth, the increase of crack amount achieves to a peak value, as shown by the point $b$ in the Fig. 5. Furthermore, as depicted in Fig. 6, the slope of the vertical force changes as the penetration depth is larger than $0.2 \mathrm{~mm}$ due to the generation of the micro crack. Then, the vertical force of the TBM hob also reaches to a peak value while the penetration depth is $0.4 \mathrm{~mm}$, as shown by the line $x$ in the Fig. 6 . It indicates that the arrival of peak value of the vertical force is the sign of macro crack initiation. It should be pointed out that the value of the lateral force of the TBM hob keeps at 0 when the penetration depth is lower than $0.4 \mathrm{~mm}$, as depicted in Fig. 6. It can be explained that no rock chips are produced on both sides of the hob blade, resulting in less difference of reaction force on both sides of the hob blade.

While the penetration depth is larger than $0.6 \mathrm{~mm}$, as presented in Fig. 4(c), (d) and (e), the main crack begins to propagate quickly towards the free-face. It can be observed that the main crack is formed by the tensile crack marked by red points. Meanwhile, it can be found that the amount of the tensile crack is obviously larger than that of shear crack, as shown in Fig. 5, demonstrating that the main crack propagation and the rock chip formation are driven by tensile failure. In this crack propagation stage, the vertical force of the TBM hob shows a downward trend, but the lateral force of the TBM hob presents an upward trend, implying that the increase of the lateral force of TBM is accompanied by the rapid propagation of the main crack in the rock sample. When the penetration depth increases to approximately $1.8 \mathrm{~mm}$, as illustrated in Fig. 4(f), the macro crack propagates to the free-face with a big rock chip, and the vertical force still keeps at a certain value due to the reaction of the crushed rock sample, as shown by the line $y$ in Fig. 6 .

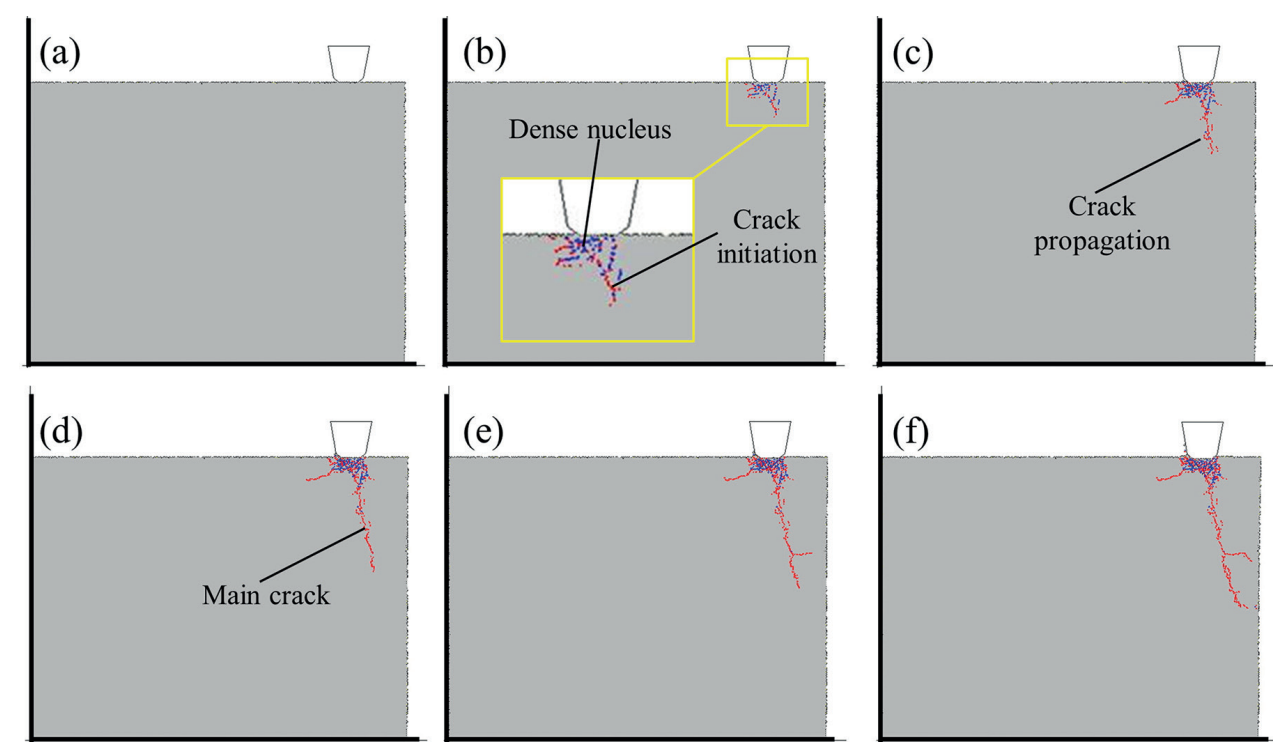

Fig. 4 Crack propagation condition by TBM hob with different penetration depth: (a) $0.2 \mathrm{~mm}$, (b) $0.4 \mathrm{~mm}$, (c) $0.6 \mathrm{~mm}$, (d) $0.8 \mathrm{~mm}$, (e) $1.0 \mathrm{~mm}$, (f) $1.8 \mathrm{~mm}$ 


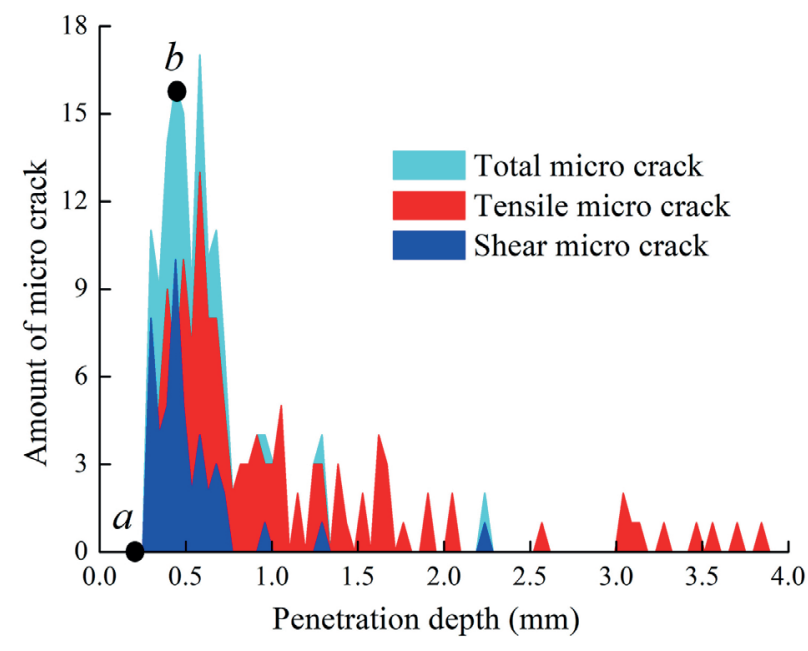

Fig. 5 Increase of micro crack number in rock with the penetration depth

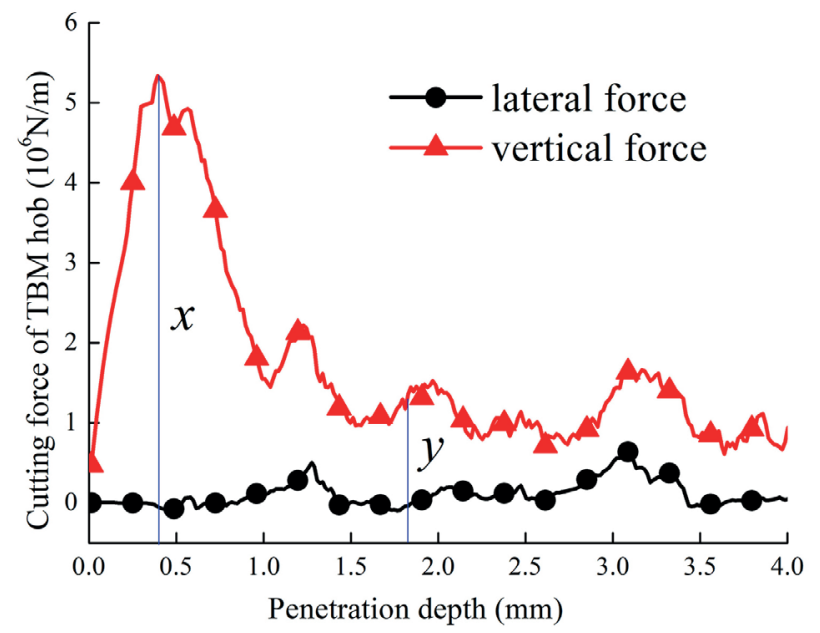

Fig. 6 Cutting force of TBM hob with the penetration depth
According to above analysis and discussion about the rock-breaking process by the TBM hob under the free-face condition, it can be concluded that the rock shows elastic deformation firstly, then a dense nucleus caused by shear failure is produced, and finally the main crack caused by tensile failure is initiated and propagated with the increase of the penetration depth of the TBM hob. Meanwhile, the main crack are prone to expand to the free-face, implying that the free-face can benefit the crack extension and rock chip generation when the values of $S$ and $H$ is proper.

\subsection{Selection of the optimum free-face spacing}

To study the effects of the $S$ on the rock-cutting characteristics of the TBM hob, six groups of simulation are performed in which the $S$ ranges from $20 \mathrm{~mm}$ to $120 \mathrm{~mm}$ and the $H$ is set to the maximum height of the rock sample with a value of $300 \mathrm{~mm}$ to eliminate the influence of the $H$ on the $S$. The crack propagation conditions with different $S$ are shown in Fig. 7. Overall, both the dense nucleus and crack propagation can be observed regardless of the value of the $S$. Comparing with the subgraphs in Fig. 7, it can be found that the value of the $S$ have a significant impact on the crack propagation for cutting rock under the free-face condition by the TBM hob. The main crack tends to propagate to the free-face as the $S$ is achieved at 20,40, 60 and $80 \mathrm{~mm}$, and a large rock chip is produced, as depicted in Fig. 7(a), (b), (c) and (d). While the $S$ is larger than $80 \mathrm{~mm}$, as shown in Fig. 7(e) and (f), the main crack tends to extend along the vertical direction

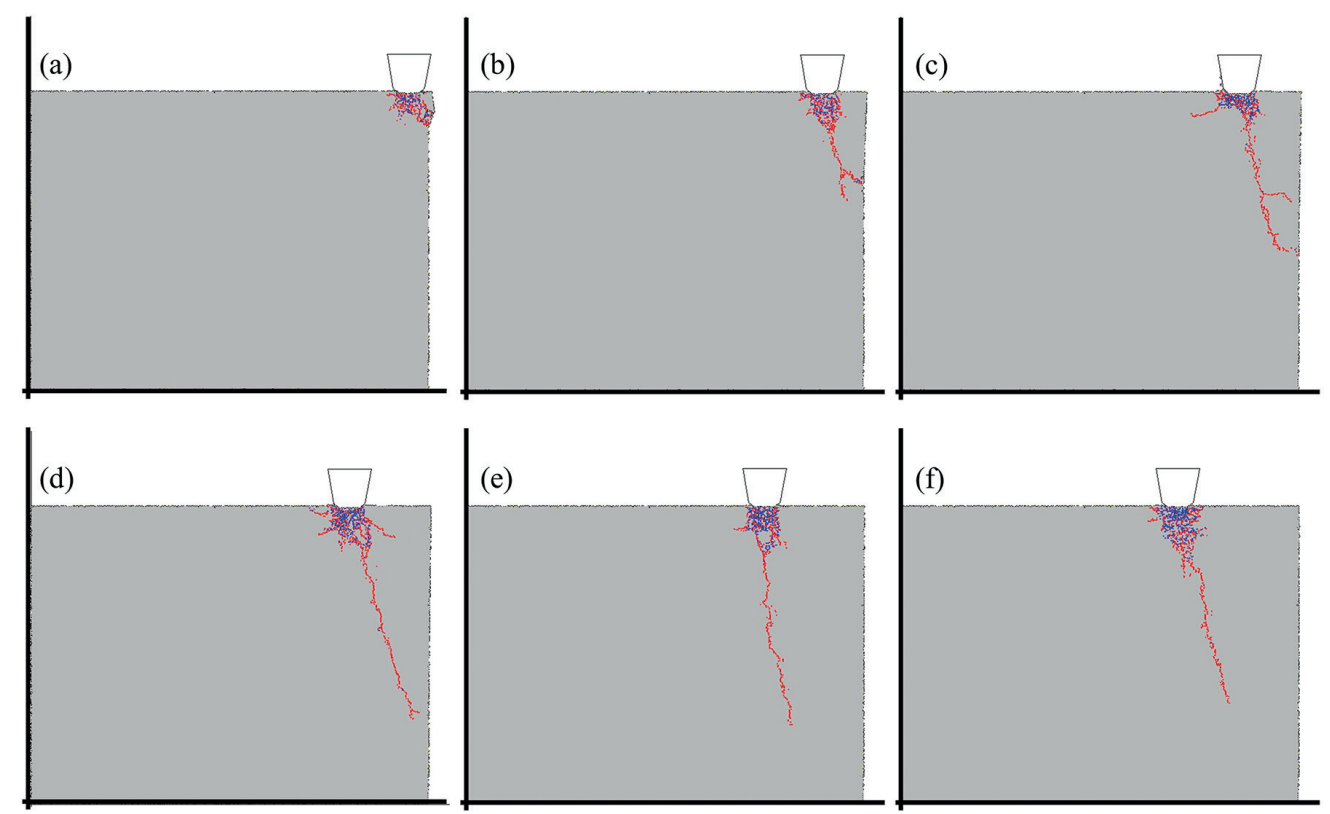

Fig. 7 Crack propagation conditions with different $S$ : (a) $20 \mathrm{~mm}$; (b) $40 \mathrm{~mm}$; (c) $60 \mathrm{~mm}$; (d) $80 \mathrm{~mm}$; (e) $100 \mathrm{~mm}$; (f) $120 \mathrm{~mm}$ 
of the rock sample. In other words, the free-face couldn't offer an effective guidance for the crack propagation when the $S$ is more than a critical value. As a result, the value of the $S$ should be smaller than $80 \mathrm{~mm}$ to make full use of the free-face for this hard rock when cutting rock with TBM hob under the free-face condition.

The details of rock chip area and crack length with different $S$ are summarized in Fig. 8 based on the simulation results. For the crack length, as the $S$ is lower than $80 \mathrm{~mm}$, the main crack length shows a rapid growth with the increase of the $S$. Then, the crack length maintains at a relatively stable value which is about $210 \mathrm{~mm}$ with the further increase of the $S$. For the rock chip area, its change trend with the $S$ shows increasing first and then decreasing, and the peak rock chip area with a value of $10056.8 \mathrm{~mm}^{2}$ is achieved when the $S$ is $80 \mathrm{~mm}$. It can be explained by the fact that the increase of the $S$ and the crack length can increase the rock chip area directly since the main crack could extend to the free-face when the $S$ ranges within $80 \mathrm{~mm}$, combined with the above

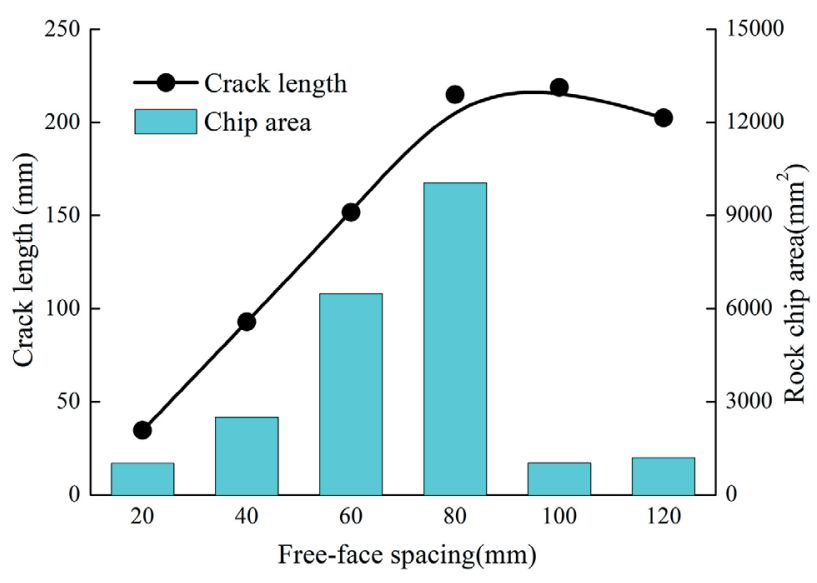

Fig. 8 Change trend of crack length and chip area with $S$

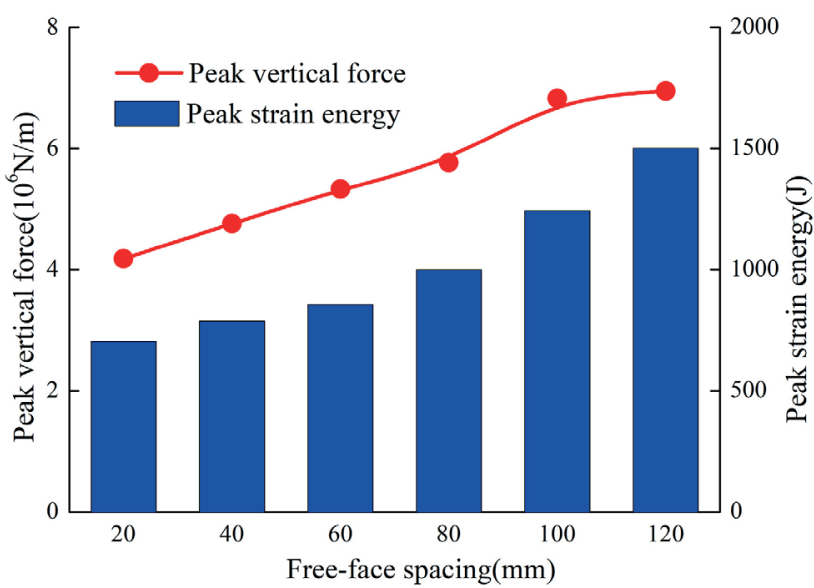

Fig. 9 Peak vertical force and peak strain energy with $S$ analysis of crack propagation conditions. However, when the $S$ exceeds $80 \mathrm{~mm}$, the main crack couldn't reach to the free-face and no big rock chip is generated, leading to a decrease of rock chip area.

The change laws of peak strain energy and peak vertical force of the TBM hob with $S$ during penetrating process are shown in Fig. 9. On the whole, the peak strain energy and peak vertical force increase linearly with the increase of the $S$. For example, the peak strain energy increases from $704 \mathrm{~J}$ to $1501 \mathrm{~J}$ when the $S$ increases from $20 \mathrm{~mm}$ to $120 \mathrm{~mm}$. At this point, the increase of the $S$ would raise the cutting force and cutting energy significantly, causing an increase of difficulty in rock-breaking with TBM hob under the free-face condition.

The specific energy consumption is adopted to describe the rock-cutting efficiency of the TBM hob under the freeface condition, which is calculated by the ratio of penetrating work and rock chip volume, and a low specific energy consumption is accompanied by a high rock-cutting efficiency [24]. As illustrated in Fig. 10, with the increase of the $S$, the specific energy consumption first decreases and then increases, and a minimum specific energy consumption is achieved at a $S$ of $80 \mathrm{~mm}$. It implies that it exists an optimum $S$ to obtain the highest rock-cutting efficiency for the TBM hob when cutting rock under the free-face condition. Additionally, the specific energy consumption for the $S$ varied from $20 \mathrm{~mm}$ to $80 \mathrm{~mm}$ is far less than that for the $S$ varied from $100 \mathrm{~mm}$ to $120 \mathrm{~mm}$, and the ratio of the former to the latter is approximately $40 \%$. The reason for this is that the TBM hob couldn't utilize the free-face to cut this hard rock when the $S$ exceeds $80 \mathrm{~mm}$, as described in Fig. 7, resulting in a small rock chip area and a large specific energy consumption. It confirms that free-face

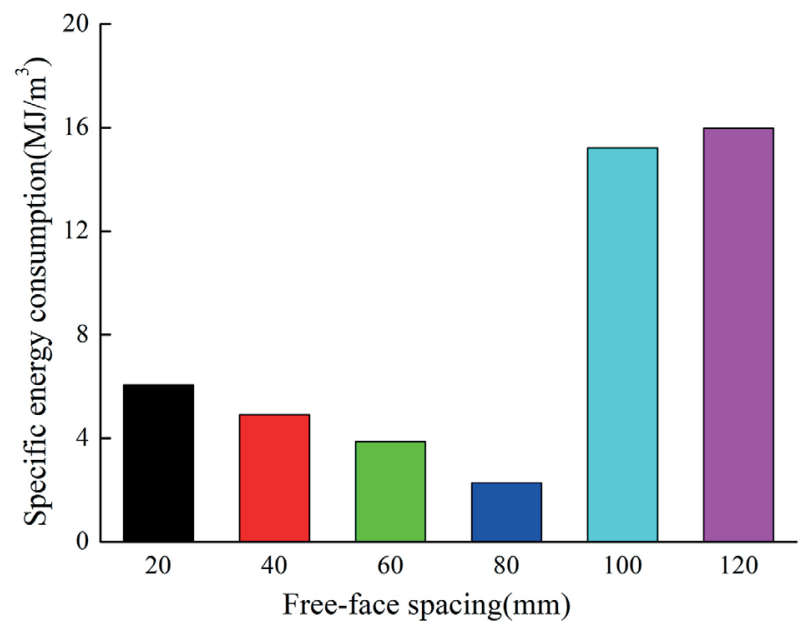

Fig. 10 Change trend of specific energy consumption with $S$ 

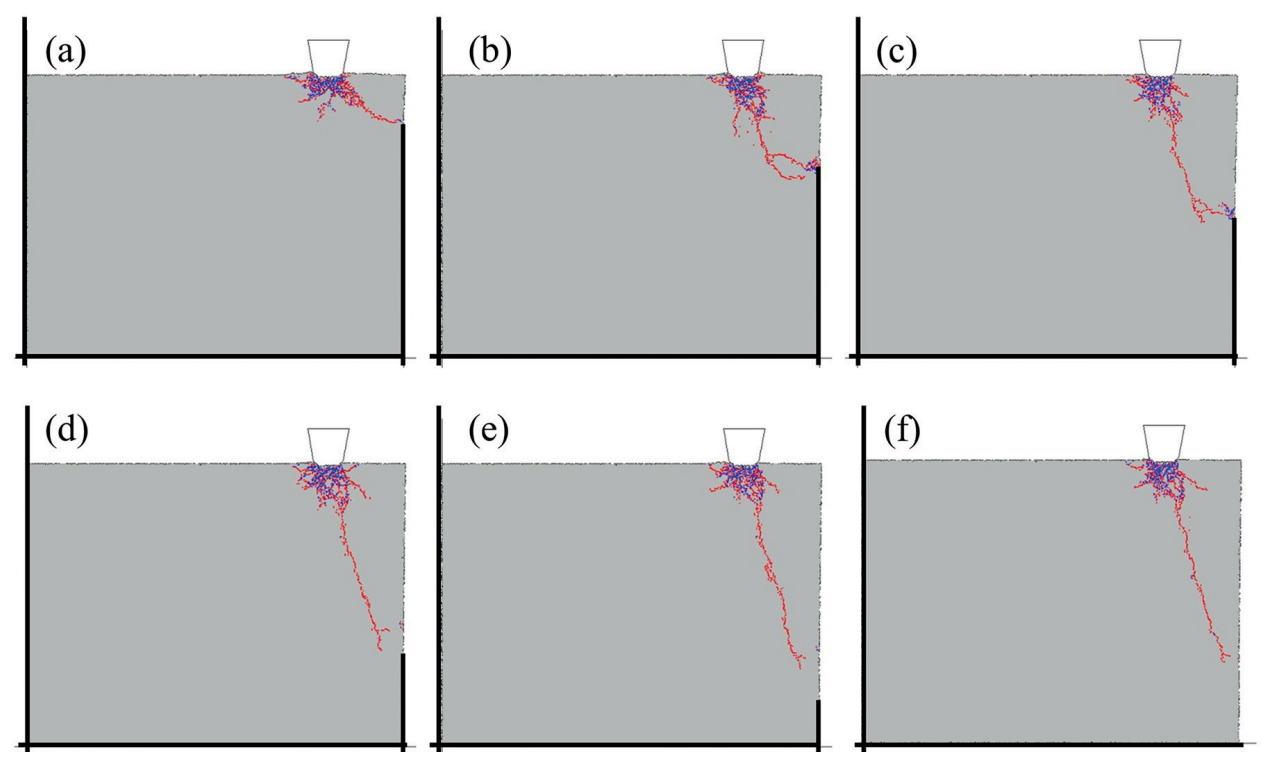

Fig. 11 Crack propagation conditions with different $H$ : (a) $50 \mathrm{~mm}$; (b) $100 \mathrm{~mm}$; (c) $150 \mathrm{~mm}$; (d) $200 \mathrm{~mm}$; (e) $250 \mathrm{~mm}$; (f) $300 \mathrm{~mm}$

can enhance the rock-breaking efficiency of the TBM hob significantly when the $S$ is controlled within $80 \mathrm{~mm}$, and the optimum $S$ is $80 \mathrm{~mm}$ for this hard rock.

\subsection{Selection of the optimum free-face height}

To obtain the optimum $H$, six groups of simulation are performed in which the $H$ is set to 50, 100, 150, 200, 250 and $300 \mathrm{~mm}$, and the $S$ is fixed to the optimum $S$ with a value of $80 \mathrm{~mm}$ based on the above result. The crack propagation conditions are presented in Fig. 11. Observably, the main crack all can reach the free-face regardless of the values of the $H$ for the optimum $S$. Furthermore, the main crack would end the propagation on the lowest point of the free-face as the $H$ is 50,100 and $150 \mathrm{~mm}$, as illustrated in Fig. 11(a), (b) and (c). In this sense, the main crack propagation would be restrained due to the insufficient $H$ although the main crack can reach the free-face. However, when the $H$ is larger than $150 \mathrm{~mm}$, the end point of the main crack would not reach the lowest point of the free-face, and the main crack growth patterns are similar each other when the $H$ is achieved at 200, 250 and $300 \mathrm{~mm}$, respectively, as illustrated in Fig. 11(d), (e) and (f). It denotes that the $H$ should be larger than a critical value to fully promote the crack propagation when cutting this hard rock by the TBM hob under the free-face condition.

Fig. 12 shows the change trend of the crack length and rock chip area with different $H$. Overall, with the increase of the $H$, both the rock chip area and the crack length increase with the growth of the $H$ when the $H$ is less than $200 \mathrm{~mm}$. However, when the $H$ exceeds $200 \mathrm{~mm}$, the crack length and the rock chip area keep almost unchanged, which are

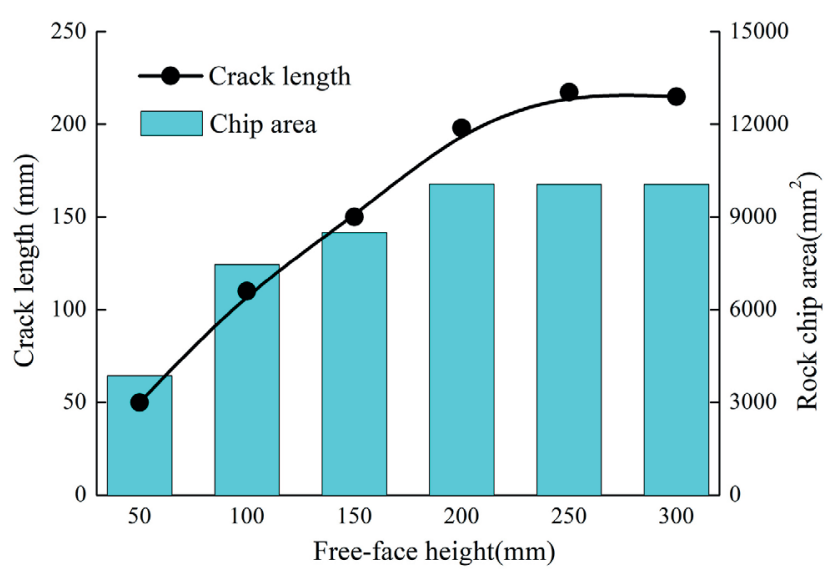

Fig. 12 Change trend of crack length and chip area with $H$

approximately $200 \mathrm{~mm}$ and $10062.5 \mathrm{~mm}^{2}$, respectively. This is can be explained that the main crack propagation patterns and propagation paths are similar for different $H$ when the $H$ is more than $200 \mathrm{~mm}$, as shown in Fig. 11(d), (e) and (f), resulting in similar values of the crack length and the rock chip area. It also implies it exists a critical value of the $H$ to cut the hard rock effectively with the aid of the free-face, which agrees with the above analysis about the crack propagation conditions with different $H$.

The change trends of the peak strain energy and the peak vertical force with different $H$ are presented in Fig. 13. Both the peak strain energy and the peak vertical force first decrease and then remain almost unchanged with the increase of the $H$. When the $H$ exceeds $200 \mathrm{~mm}$, the values of the peak strain energy and the peak vertical force keep at approximately $1000 \mathrm{~J}$ and $5.7 \times 10^{6} \mathrm{~N} / \mathrm{m}$, respectively. These are in good agreement with the change trends 


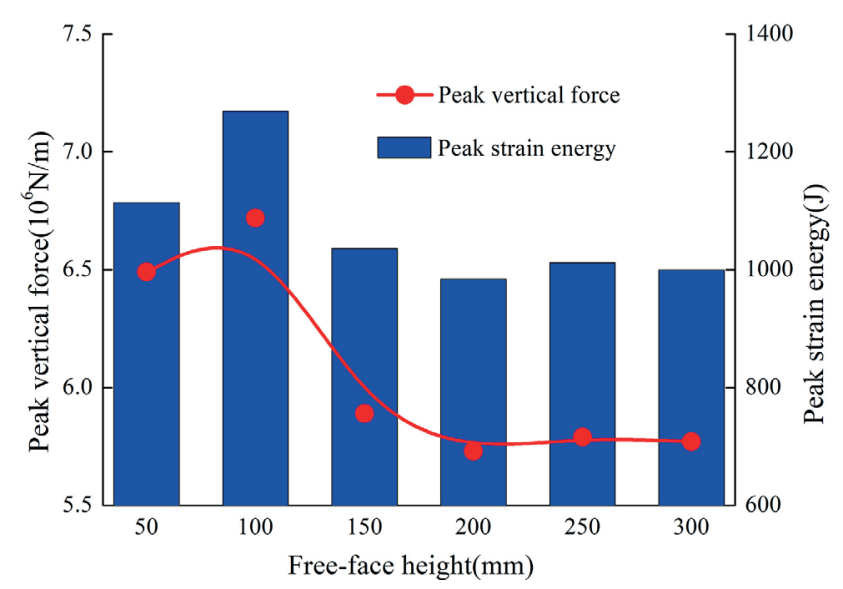

Fig. 13 Peak vertical force and peak strain energy with $H$

of the crack length and rock chip area, as stated above. In addition, the peak strain energy and the peak vertical force corresponding to the $H$ of 50, 100 and $150 \mathrm{~mm}$ are generally larger than that corresponding to the $H$ of 200 , 250 and $300 \mathrm{~mm}$. This result can also be explained by the change of the crack conditions under different $H$. When the $H$ is less than $200 \mathrm{~mm}$, the insufficiency of the $H$ would restrain the crack propagation to the depth of the hard rock, causing larger peak vertical force and peak strain energy. But when the $H$ is larger than $200 \mathrm{~mm}$, the sufficiency of the $H$ can promote the crack propagation effectively, resulting in smaller peak vertical force and peak strain energy. It also implies that the insufficiency of the $H$ would enlarge the difficulty of cutting rock by the TBM hob under the free-face condition.

The specific energy consumption under different $H$ is illustrated in Fig. 14. The specific energy consumption decreases nonlinearly and the decrease rate gradually slows with the increase of the $H$. The specific energy consumption barely decreases with a value about $2.3 \mathrm{MJ} / \mathrm{m}^{3}$ when the $H$ is more than $200 \mathrm{~mm}$. This phenomenon can also be interpreted by the change of the crack conditions under different $H$, when the $H$ is less than $200 \mathrm{~mm}$, the main cracks under different $H$ all reaches to the lowest point of the free-face, leading to an growth of rock chip area and an reduction of specific energy consumption. However, when the $H$ is larger than $200 \mathrm{~mm}$, the crack propagation patterns are similar for different $H$, leading to a similar rock chip and similar specific energy consumption. Therefore, under the optimum $S$, the $H$ should exceed a certain critical value to fully utilize the free-face, indicating that it exists an optimum $H$ to cutting hard rock under the free-face condition, which is approximately $200 \mathrm{~mm}$ for this hard rock in this paper.

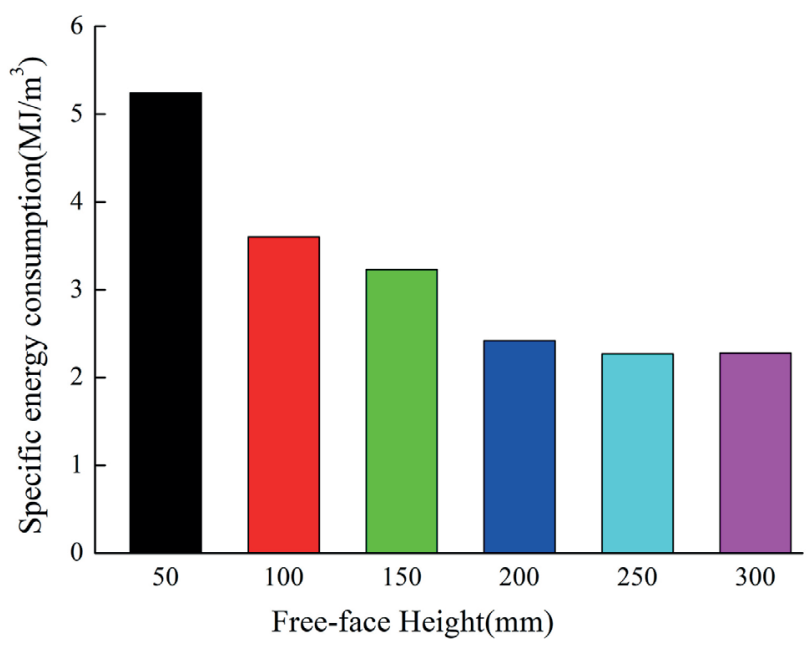

Fig. 14 Change trend of specific energy consumption with $H$

\section{Hard rock cutting test and comparison}

\subsection{Experimental apparatus}

To further understand the actual rock-cutting process of the TBM hob under the free-face condition clearly, the hard rock cutting tests under the free-face condition are carried out according to the linear cutting machine, as illustrated in Fig. 15(a). The TBM hob whose structural parameters are consistent with those in the simulation is installed on the tool holder, and the tool holder controlled by the hydraulic cylinder can move up and down to obtain a required penetration depth of the TBM hob. Meanwhile, the hard rock sample with a length of $900 \mathrm{~mm}$, width of $400 \mathrm{~mm}$ and height of $300 \mathrm{~mm}$ is put on the workbench of the linear cutting machine, and the macro mechanics parameters of the rock sample are presented in Table 1. Furthermore, the bottom of the rock sample is bolted to the workbench but the two sides of the rock sample (including left and right sides) are not restricted to simulate the freeface, as presented in Fig. 15(b). The workbench driven by the other two hydraulic cylinders can move left and right to achieve different $S$, and move back and forth to realize rock cutting test by the TBM hob. The cutting tests with
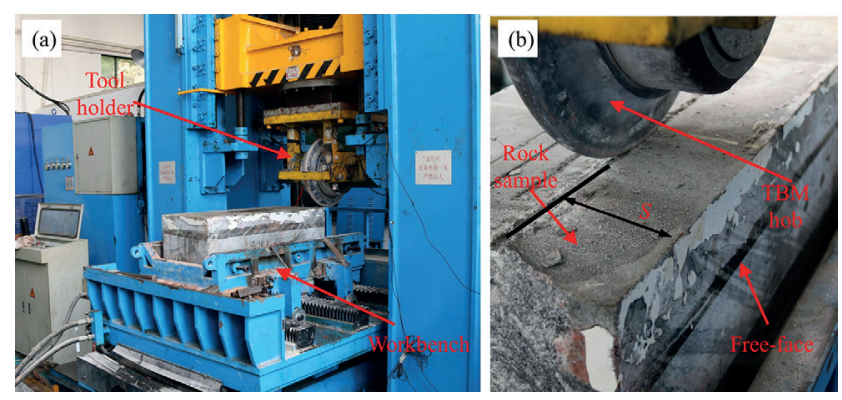

Fig. 15 Rock-cutting test by TBM hob under the free-face condition: (a) linear cutting machine; (b) schematic diagram of rock-cutting test 

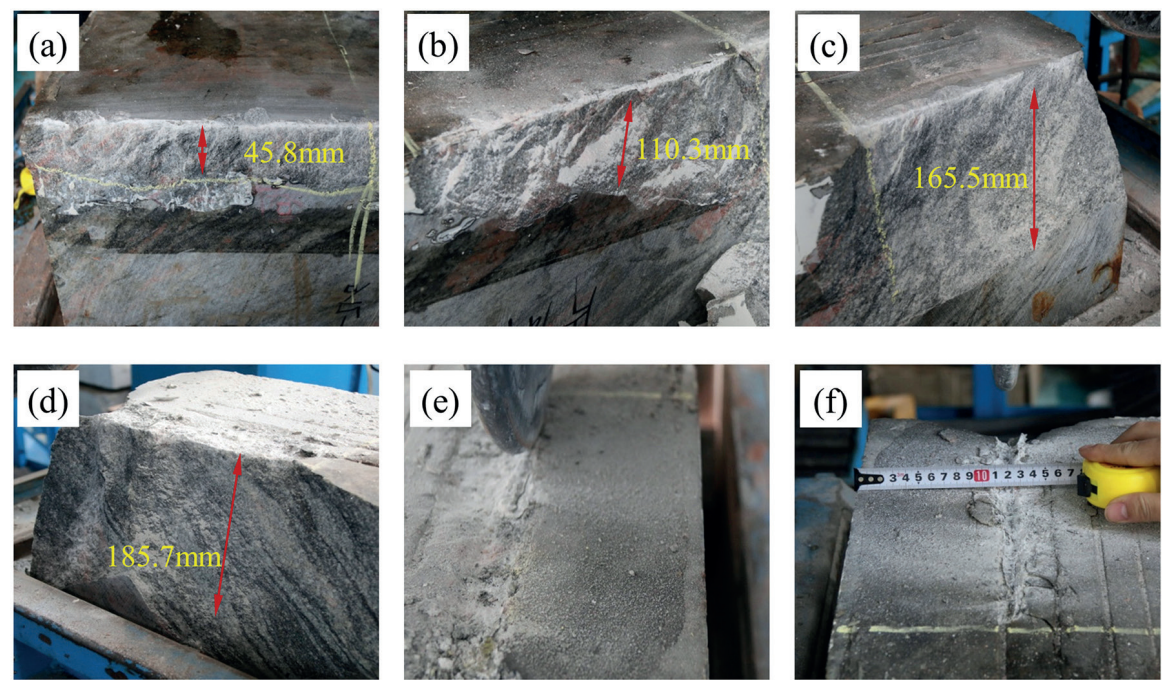

Fig. 16 Rock-breaking states with different S: (a) $20 \mathrm{~mm}$; (b) $40 \mathrm{~mm}$; (c) $60 \mathrm{~mm}$; (d) $80 \mathrm{~mm}$; (e) $100 \mathrm{~mm}$; (f) $120 \mathrm{~mm}$

only one kind of $H$, that is, the height of the rock sample, and six kinds of $S$ are performed, considering the size (900 mm), weight (about $270 \mathrm{~kg}$ ) and price (over $600 \mathrm{USD}$ ) of the rock sample. The values of the $S$ are set to 20,40, $60,80,100$, and $120 \mathrm{~mm}$, and the value of the penetration depth is set to $6 \mathrm{~mm}$ corresponding to the numerical simulation. To make full use of the rock sample, the cutting length of each cutting experiment is set to $400 \mathrm{~mm}$. The cutting velocity of $20 \mathrm{~mm} / \mathrm{s}$ is adopted in these cutting experiments considering the stability of the linear cutting machine. To measure rock cutting forces of the TBM hob in three directions, three sets of strain gauges are attached to the tool holder in the way of full bridge, which can record the voltage signal and convert the voltage signal into the force signal combined with the dynamic strain gauge during rock-cutting process. In addition, the rock chips are also collected and the specific energy consumption is calculated in these cutting tests.

\subsection{Experimental phenomena under different free-face spacing}

The rock-breaking states induced by the TBM hob under different $S$ are shown in Fig. 16. When the $S$ varies from $20 \mathrm{~mm}$ to $80 \mathrm{~mm}$, as presented in Fig. 16(a), (b), (c) and (d), the main crack can directly expand to the free-face, and some big rock chips are detached from the rock sample. For these values of the $S$, the values of the crack length increase in turn with the growth of the $S$, which are 45.8, $110.3,165.5$ and $185.7 \mathrm{~mm}$, respectively, leading to the growth of the rock chip size. Meanwhile, the simulated and experimental crack lengths are very similar each other, and have a same change trend with the growth of the $S$, as presented in Fig. 17. However, when the values of the $S$ are 100 and $120 \mathrm{~mm}$, no large rock chip is formed and only one cutting groove is produced on the rock surface, as shown in Fig. 16(e) and (f), implying that the main crack couldn't extend to the free-face. It also indicates that the $S$ should be less than a critical value to utilize the freeface effectively, approximately $80 \mathrm{~mm}$ in this paper, which is in agreement with the numerical result in Section 3.2.

\subsection{Comparison of rock-breaking efficiency under different free-face spacing}

The simulated and experimental specific energy consumption under different $S$ are presented in Fig. 18. Obviously, the change trend of the specific energy consumption of simulation and experiment is the same. With the increase of the $S$, both the simulation and experiment results of the specific energy consumption first increase and then

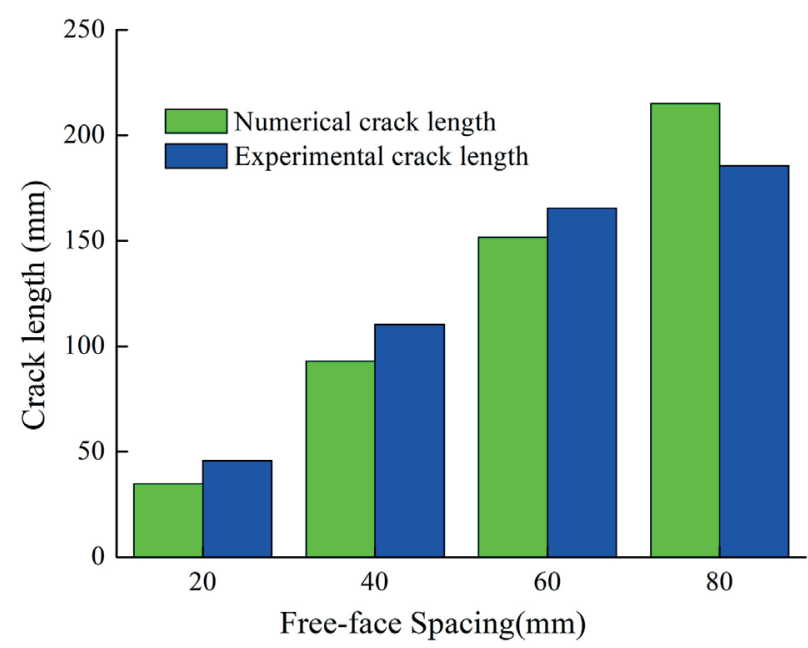

Fig. 17 Comparison of simulated and experimental crack lengths 


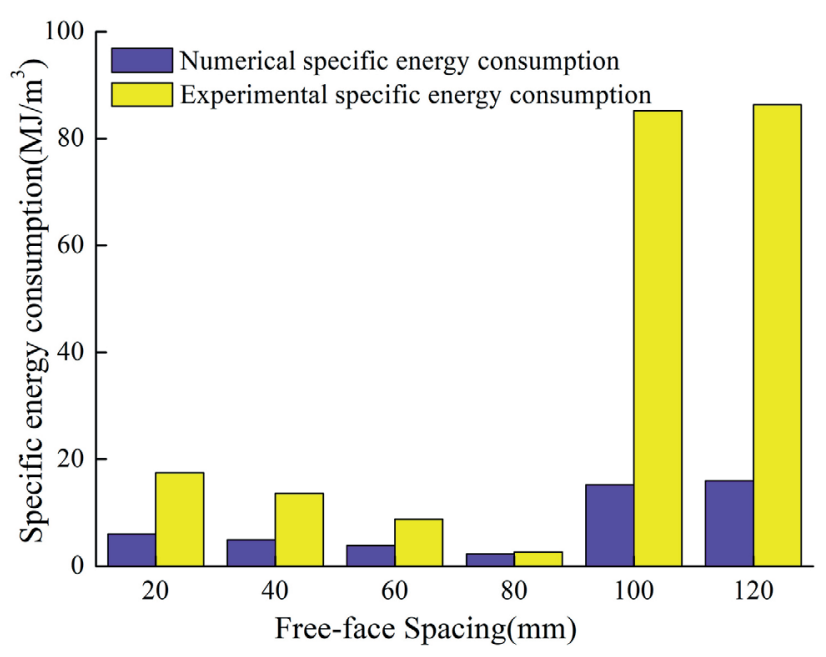

Fig. 18 Comparison of simulated and experimental specific energy consumption

decrease, and the minimum specific energy consumption is achieved while the $S$ is $80 \mathrm{~mm}$, indicating that the optimal $S$ corresponding to the highest rock-breaking efficiency is $80 \mathrm{~mm}$ when the $H$ is $300 \mathrm{~mm}$ once again. Furthermore, both of the simulated and experimental specific energy consumptions corresponding to the $S$ of 20,40, 60 and $80 \mathrm{~mm}$ are far less than that corresponding to the $S$ of 100 and $120 \mathrm{~mm}$, as also mentioned in Section 3.2, implying that the $S$ should be controlled within the critical $S$ to improve the rock-cutting efficiency significantly. It should be noted that the results between simulation and experiment for specific energy consumption have some differences although both of them have the same change trend. It mainly caused by the fact that the simulated result is obtained from the two-dimensional rock cutting simulation rather than three-dimensional rock cutting simulation. However, the experimental result is got from the three-dimensional rock cutting tests, leading to some differences in the calculation of the rock cutting energy and rock chip volume. For instance, the rock cutting energy in the simulation comes from the vertical penetration process of the TBM hob, but the rock cutting energy in the experiment comes from the horizontal cutting process of the TBM hob, causing a difference in the rock cutting energy between the simulated result and the experimental result. Moreover, the rock chip produced in experiment couldn't be collected completely since some small rock chip may splash away quickly from the rock sample surface, resulting in a less rock chip volume and a larger specific energy consumption in experiment compared with that in simulation.
In these rock cutting simulations and experiments, the gneiss is chosen as the rock sample, and the optimum free-face condition of cutting this kind of rock with TBM hob is obtained. More optimum free-face conditions regarding different kinds of rocks will be investigated in future study.

\section{Conclusions}

In this study, the rock-cutting characteristics by the TBM hob under the free-face condition are studied and the optimum cutting condition of the TBM hob for this hard rock is obtained based on the simulated and experimental methods. The main conclusions of the paper can be drawn as follows:

1. During the rock-cutting process of the TBM hob under the free-face condition, the rock first show elastic deformation, then a dense nucleus mainly caused by shear failure is formed, and finally the main crack caused by tensile failure is initiated and propagated when the vertical force of the TBM hob is achieved to the peak value. The formation of the large rock chip is mainly caused by tensile failure which can improve rock-cutting efficiency of the TBM hob significantly.

2. Both the $S$ and the $H$ have great effects on the main crack propagation, rock chip area, cutting force and specific energy consumption etc., and there exists critical values of the $S$ and $H, 80 \mathrm{~mm}$ and $200 \mathrm{~mm}$ respectively, to fully make use of the free-face to cut this hard rock.

3. The rock-breaking characteristics under free-face condition with TBM hob is further investigated by the rock-cutting tests, and the simulated results are basically consistent with the experimental results. The research results can provide effective guidance for the design of the rock-cutting technology under the free-face by the TBM hob to overcome the shortcomings of low rock-cutting efficiency and short rock-cutting life of the TBM hob when cutting hard rock condition.

\section{Acknowledgment}

This work is supported by the National Natural Science Foundation of China (Grants No. 52005179 and 51704256), the Natural Science Foundation of Hunan Province (Grants No. 2020JJ5365 and 2020JJ4583), the Scientific Research Project of Hunan Education Department (Grants No. 20C1153 and 19C1756) and the Major Scientific and Technological Project of Hunan Province (Grants No. 2019GK1010). 


\section{References}

[1] Innaurato, N., Oggeri, C., Oreste, P. P., Vinai, R. "Experimental and Numerical Studies on Rock Breaking with TBM Tools under High Stress Confinement", Rock Mechanics and Rock Engineering, 40(5), pp. 429-451, 2007.

https://doi.org/10.1007/s00603-006-0109-4

[2] Ma, H., Yin, L., Ji, H. "Numerical study of the effect of confining stress on rock fragmentation by TBM cutters", International Journal of Rock Mechanics and Mining Sciences, 48(6), pp. 1021-1033, 2011.

https://doi.org/10.1016/j.ijrmms.2011.05.002

[3] Zhu, X., Liu, W., He, X. "The investigation of rock indentation simulation based on discrete element method", KSCE Journal of Civil Engineering, 21(4), pp. 1201-1212, 2017. https://doi.org/10.1007/s12205-016-0033-4

[4] Moon, T., Oh, J. "A Study of Optimal Rock-Cutting Conditions for Hard Rock TBM Using the Discrete Element Method", Rock Mechanics and Rock Engineering, 45, pp. 837-849, 2012. https://doi.org/10.1007/s00603-011-0180-3

[5] Liu, J., Wang, J., Wan, W. "Numerical study of crack propagation in an indented rock specimen", Computers and Geotechnics, 96, pp. 1-11, 2018

https://doi.org/10.1016/j.compgeo.2017.10.014

[6] Naghadehi, M. Z., Mikaeil, R. "Optimization of Tunnel Boring Machine (TBM) Disc Cutter Spacing in Jointed Hard Rock Using a Distinct Element Numerical Simulation", Periodica Polytechnica Civil Engineering, 61(1), pp. 56-65, 2017. https://doi.org/10.3311/PPci.9521

[7] Choi, S.-O., Lee, S.-J. "Three-dimensional numerical analysis of the rock-cutting behavior of a disc cutter using particle flow code", KSCE Journal of Civil Engineering, 19(4), pp. 1129-1138, 2015. https://doi.org/10.1007/s12205-013-0622-4

[8] Geng, Q., Wei, Z., Ren, J. "New rock material definition strategy for FEM simulation of the rock cutting process by TBM disc cutters", Tunnelling and Underground Space Technology, 65, pp. 179-186, 2017. https://doi.org/10.1016/j.tust.2017.03.001

[9] Xiao, N., Zhou, X.-P., Gong, Q.-M. "The modelling of rock breakage process by TBM rolling cutters using 3D FEM-SPH coupled method", Tunnelling and Underground Space Technology, 61, pp. 90-103, 2017.

https://doi.org/10.1016/j.tust.2016.10.004

[10] Cho, J.-W., Jeon, S., Jeong, H.-Y., Chang, S.-H. "Evaluation of cutting efficiency during TBM disc cutter excavation within a Korean granitic rock using linear-cutting-machine testing and photogrammetric measurement", Tunnelling and Underground Space Technology, 35, pp. 37-54, 2013. https://doi.org/10.1016/j.tust.2012.08.006

[11] Liu, J., Wang, J. "The effect of indentation sequence on rock breakages: A study based on laboratory and numerical tests", Comptes Rendus Mécanique, 346(1), pp. 26-38, 2018. https://doi.org/10.1016/j.crme.2017.11.004

[12] Liu, J., Chen, Y., Wan, W., Wang, J., Fan, X. "The influence of bedding plane orientation on rock breakages in biaxial states", Theoretical and Applied Fracture Mechanics, 95, pp. 186-193, 2018. https://doi.org/10.1016/j.tafmec.2018.03.005
[13] Lin, Q., Cao, P., Cao, R. "Experimental investigation of jointed rock breaking under a disc cutter with different confining stresses", Comptes Rendus Mécanique, 346(9), pp. 833-843, 2018. https://doi.org/10.1016/j.crme.2018.06.012

[14] Pan, Y., Liu, Q., Peng, X., Liu, Q., Liu, J. Huang, X., Cui, X., Cai, T. "Full-Scale Linear Cutting Tests to Propose Some Empirical Formulas for TBM Disc Cutter Performance Prediction", Rock Mechanics and Rock Engineering, 52, pp. 4763-4783, 2019. https://doi.org/10.1007/s00603-019-01865-x

[15] Yang, H., Liu, J., Liu, B. "Investigation on the Cracking Character of Jointed Rock Mass Beneath TBM Disc Cutter", Rock Mechanics and Rock Engineering, 51, pp. 1263-1277, 2018. https://doi.org/10.1007/s00603-017-1395-8

[16] Yin, L., Miao, C., He, G., Dai, F., Gong, Q. "Study on the influence of joint spacing on rock fragmentation under TBM cutter by linear cutting test", Tunnelling and Underground Space Technology, 57, pp. 137-144, 2016 https://doi.org/10.1016/j.tust.2016.02.018

[17] Ning, B., Xia, Y., Lin, L., Zhang, X., He, Y., Liu, Y. "Experimental study on the adaptability of cutters with different blade widths under hard rock and extremely hard rock conditions", Acta Geotechnica, 15, pp. 3283-3294, 2020. https://doi.org/10.1007/s11440-020-00958-0

[18] Xia, Y., Guo, B., Tan, Q., Zhang, X., Lan, H., Ji, Z. "Comparisons Between Experimental and Semi-theoretical Cutting Forces of CCS Disc Cutters", Rock Mechanics and Rock Engineering, 51(5), pp. 1583-1597, 2018. https://doi.org/10.1007/s00603-018-1400-X

[19] Tan, Q., Yi, L., Xia, Y.-M. "Performance Prediction of TBM Disc Cutting on Marble Rock under Different Load Cases", KSCE Journal of Civil Engineering, 22(4), pp. 1466-1472, 2018. https://doi.org/10.1007/s12205-017-1048-1

[20] Xia, Y., Shi, Y., Lin, L., Zhang, Y., Tan, Q., Yang, Y. "Experimental Evaluation of Fragments from TBM Disc Cutting under Different Load Cases", Periodica Polytechnica Civil Engineering, 62(3), pp. 746-756, 2018. https://doi.org/10.3311/PPci.11961

[21] Hassani, F., Nekoovaght, P. M., Gharib, N. "The influence of microwave irradiation on rocks for microwave-assisted underground excavation", Journal of Rock Mechanics and Geotechnical Engineering, 8(1), pp. 1-15, 2016. https://doi.org/10.1016/j.jrmge.2015.10.004

[22] Lu, G., Li, Y., Hassani, F., Zhang, X. "The influence of microwave irradiation on thermal properties of main rock-forming minerals", Applied Thermal Engineering, 112, pp. 1523-1532, 2017. https://doi.org/10.1016/j.applthermaleng.2016.11.015

[23] Ciccu, R., Grosso, B. "Improvement of Disc Cutter Performance by Water Jet Assistance", Rock Mechanics and Rock Engineering, 47, pp. 733-744, 2014. https://doi.org/10.1007/s00603-013-0433-4

[24] Zhang, X., Xia, Y., Tan, Q., Wu, D. "Comparison Study on the Rock Cutting Characteristics of Disc Cutter under Free-face-assisted and Conventional Cutting Methods", KSCE Journal of Civil Engineering, 22(10), pp. 4155-4162, 2018. https://doi.org/10.1007/s12205-018-0577-6 
[25] Gong, Q. M., Zhao, J., Hefny, A. M. "Numerical simulation of rock fragmentation process induced by two TBM cutters and cutter spacing optimization", Tunnelling and Underground Space Technology, 21, pp. 263-270, 2006.

https://doi.org/10.1016/j.tust.2005.12.124

[26] Zhang, X., Hu, D., Li, J., Pan, J., Xia, Y., Tian, Y. "Investigation of rock breaking mechanism with TBM hob under traditional and freeface condition", Engineering Fracture Mechanics, 242, Article No. 107432, 2021.

https://doi.org/10.1016/j.engfracmech.2020.107432

[27] Li, X. F., Li, H. B., Liu, Y. Q., Zhou, Q. C., Xia, X. "Numerical Simulation of Rock Fragmentation Mechanisms Subject to Wedge Penetration for TBMs", Tunnelling and Underground Space Technology, 53, pp. 96-108, 2016.

https://doi.org/10.1016/j.tust.2015.12.010
[28] Li, X., Wang, S., Ge, S., Malekian, R., Li, Z. "Investigation on the influence mechanism of rock brittleness on rock fragmentation and cutting performance by discrete element method", Measurement, 113, pp. 120-130, 2018. https://doi.org/10.1016/j.measurement.2017.07.043

[29] Li, X., Wang, S., Ge, S., Malekian, R., Li, Z. "Numerical simulation of rock fragmentation during cutting by conical picks under confining pressure", Comptes Rendus Mécanique, 345, pp. 890-902, 2017.

https://doi.org/10.1016/j.crme.2017.09.004 